* Mestranda em Direito pela Universidade de Santa Cruz do Sul e advogada. E-mail: maricamargod@gmail.com ** Pós-doutora em Direito pela Universidade de Burgos/ Espanha. Professora da Graduação em Direito na Fundação Educacional Machado de Assis de Santa Rosa. E-mail: maricamargod@gmail.com

\section{Interações econômicas na interface com a implementação de políticas públicas: a democracia em curso}

\author{
ECONOMIC INTERACTIONS IN THE INTERFACE \\ WITH THE IMPLEMENTATON OF PUBLIC POLICY: \\ DEMOCRACY IN PROGRESS
}

\author{
Mariane Camargo D'Oliveira * \\ Marli Marlene Moraes da Costa **
}

Resumo: Vislumbra-se que a $\mathrm{CF} / 88$ é o instrumento de integração do complexo esquema do Estado federal. Entretanto, a difundida insatisfação com o modelo econômico brasileiro está demandando reformulações a partir de uma proposta de (re)construção dos cânones tributários. Nesse aspecto, é fundamental analisar como a ordem econômica influencia a gestão de políticas públicas, especificamente na ampla e multifacetada esfera das relações tributárias, visto que é o lócus onde confluem os jogos de poder, os interesses, os valores societais, os lucros e as tributações. Mostra-se crucial, nesse processo, que sejam implementadas políticas públicas mais interconectadas com a perquirida mitigação das disparidades sociais.

Palavras-chave: Igualdade. Ordem Econômica. Principiologia. Relações Tributárias.

Abstract: It is possible to glimpse that the Federal Constitution of 1988 is the instrument of integration of the complex scheme that the federal State is. However, the widespread dissatisfaction with the Brazilian economic model is demanding reformulations from a proposal of (re)construction of tax canons. In this regard, it is essential to analyze how the economic order influences the management of public policies, specifically in the large and multifaceted sphere of tax relationships, since it is the locus where power games, interests, societal values, profits and taxations converge. It is proven crucial, in this process, that public policies more interconnected with the so much sought mitigation of social disparities should be implemented.

Keywords: Equality. Economic Order. Principiology. Tax relationships. 


\section{INTRODUÇÃO}

À proporção que se operacionaliza, na contemporaneidade, o processo de reforma tributária, é necessário compreender e interpretar, de igual modo, o domínio da ordem econômica, já que é esta a estrutura sobre a qual as inter-relações entre Estado e sociedade e também entre os próprios sujeitos sociais são solidificadas. Entretanto, não se constitui em tarefa fácil, visto que a complexidade desse sistema implica no funcionamento societal intermediado pela intervenção do Estado.

É essencial considerar, nesta visão, que o Brasil perpassou - e ainda perpassa - por momentos (re)democráticos, ao sopesar que existem embates acontecendo para, além de salvaguardar os direitos já alcançados, vindicar por mais igualdade, mais dignidade e, consequentemente, por um espaço público mais transparente, mais politizado e mais justo. Nessa direção, é que se pode verificar que a Constituição Federal de 1988 é o instrumento de integração do complexo esquema do Estado federal, onde atuam forças contraditórias e coexistem os princípios unitário e federativo.

No entanto, a difundida insatisfação com o modelo econômico brasileiro está demandando, urgentemente, reformulações a partir de uma proposta de (re)construção dos cânones tributários. Nesse aspecto, é fundamental analisar como a ordem econômica influencia a gestão de políticas públicas, especificamente na ampla e multifacetada esfera das relações tributárias. Haja vista que este é um campo onde confluem os jogos de poder, os interesses, os valores societais, bem como os lucros e as tributações. Para que sejam implementadas, então, políticas públicas mais interconectadas com a perquirida redução das disparidades sociais, mostrase essencial verificar todos estes contextos.

É imprescindível, assim, abandonar a rigidez técnica de determinados paradigmas para consagrar soluções contemporâneas mais afinadas com a perspectiva da igualdade. Tais padrões devem ser dotados de maior flexibilidade operacional e que, assegurando o primado de mitigação das desigualdades, não inibam a exploração das potencialidades individuais. É através de uma ordem econômica mais voltada ao social que se pode galgar ambiências que verdadeiramente fomentem o bem-estar dos sujeitos. 


\section{RECONCEITUALIZAÇÕES ATINENTES À ORDEM ECONÔMICA}

Situa-se no título constitucional Da Ordem Econômica e Financeira os objetivos de realizar o desenvolvimento nacional e a justiça social brasileiras. Isto porque o artigo 170 da Constituição Federal de 1988 elenca em seus incisos temáticas que constituem o pano de fundo para se almejar uma conjuntura sociocultural em que impera o bem-estar dos indivíduos, notadamente através da valorização do trabalho e da livre iniciativa para garantir uma existência digna, sendo tudo isto permeado pelos ditames da justiça social.

Percebe-se, por conseguinte, que a ordem econômica funciona como um instrumento de implementação de políticas públicas, já que se pretende abrandar desigualdades e, ao mesmo tempo, promover campos de ação próativa, como o do meio ambiente e o da defesa do consumidor. Mas a ordem econômica que está posta hodiernamente é fruto de transições paradigmáticas ocorridas por intermédio de lutas por (re)democratização.

A referência a uma "ordem econômica e social" nas Constituições de 1934 até a de 1967, com a Emenda n. 1, de 1969 - salvo a de 1937, que apenas menciona a "ordem econômica" - e as duas ordens, uma "econômica", outra "social", na Constituição de 1988, reflete, de modo bastante nítido, a afetação ideológica da expressão. O que se extrai da leitura despida de senso crítico, dos textos constitucionais, é a indicação de que o capitalismo se transforma na medida em que assume novo caráter, social, conforme elucida Grau (2010, p. 63-64).

Nessa direção é a conceitualização de Moreira (1979, p. 67-71) quando refere que a ordem econômica demanda três acepções, a saber: é o modo de ser empírico de uma determinada economia concreta; é a expressão que designa o conjunto de normas (ou regras de conduta) qualquer que seja a sua natureza (jurídica, religiosa, moral, etc.) que respeitam à regulação do comportamento dos sujeitos econômicos (é o sistema normativo no sentido sociológico); e é a ordem jurídica da economia.

Isto quer dizer que a expressão utilizada no artigo 170 da Constituição Federal de 1988 designa a "ordem econômica" como um conjunto das relações econômicas, ou seja, a articulação do econômico e as suas inter-relações. Nesse aspecto, Grau (2010, p. 72) aduz que as precedentes ordens econômicas (mundo do dever-ser) passam a instrumentar a implementação de políticas públicas. Vale dizer: no instante em que a ordem econômica - parcela da ordem jurídica 
-, já instalada no nível constitucional, passa a predicar o aprimoramento da ordem econômica (mundo do ser), visando à sua preservação. O direito é afetado, então, por uma transformação, justamente em razão de instrumentar modificação da ordem econômica.

Daí a alusão a uma Constituição Econômica estatutária ou orgânica e uma Constituição Econômica diretiva ou programática. Naquela há a definição dos estatutos da propriedade dos meios de produção, dos agentes econômicos, do trabalho, da coordenação da economia, das organizações do capital e do trabalho; nesta, há o quadro de diretrizes das políticas públicas, coerentes com determinados objetivos também por ela enunciados, em consonância com o explicitado por Grau (2010, p. 76).

Na lição de Canotilho (2001, p. 12), "Constituição estatutária é aquela que se limita a definir um estatuto do poder, simples instrumento de governo, enunciadora de competências e reguladora de processos". Por outro lado, na visão de Moreira (1979, p. 67), a Constituição Econômica é o segmento da Constituição que trata dos princípios e regras fundamentais da ordem econômica. Esta se constitui de todas as normas ou instituições jurídicas que têm por objeto as relações econômicas. Desta maneira, pode-se concluir que a ordem econômica é muito mais extensa do que a Constituição Econômica, pois só algumas normas possuem caráter fundamental e se inserem, então, no corpo da Constituição.

Sob este aspecto, Grau (2010,p. 85-86) enfatiza que o conceito de ordem econômica constitucional não permite, não enseja, não viabiliza a aplicação de normas jurídicas. Logo, não é um conceito jurídico. Presta-se unicamente a indicar, topologicamente, no texto constitucional, disposições que, em seu conjunto, institucionalizam a ordem econômica (mundo do ser). Ou seja, a utilidade da expressão se apresenta na medida em que indica o local, na Constituição, no qual se irá encontrar tais preceitos institucionalizadores do domínio econômico factual.

Nesse caminho, Ferreira (2004, p. 193) analisa que desenvolvimento econômico não é apenas crescimento econômico e nem tampouco distribuição de riquezas. Pressupõe a discriminação de tais valores em favor do bem-estar social, uma vez que a Constituição Federal propõe a busca pelo desenvolvimento econômico como uma efetiva transformação na realidade da economia brasileira. Acrescentando a este posicionamento, é oportuno levar em conta que, no Estado social e democrático, a meta de desenvolvimento progressivo, estabelecida no artigo $1^{\circ}$ da Constituição, não deve ser considerada - no seu aspecto soberania 
- como patrimônio estatal, senão como atributo concreto de todos os cidadãos, cada um dos quais - se indicado - deveria poder afirmar, sem detrimento de seus vínculos sociais: o Estado sou eu, na visão de Pérez Luño (2001, p. 34).

O desenvolvimento deve ser entendido, então, como assevera Elali (2008, p. 14), como um estado de equilíbrio na produção, distribuição e consumo de riquezas. Nenhum Estado pode ser considerado desenvolvido se mantiver uma estrutura social caracterizada por correntes simultâneas de riqueza e pobreza. O Estado desenvolvido é marcado pela estrutura harmônica entre o padrão de modernização e a proteção dos valores coletivos. Assim, busca-se, ao mesmo tempo, o crescimento com a liberdade das atividades econômicas, desde que tal conviva com a proteção do consumidor e do meio ambiente. Um Estado que enfatiza apenas a vertente da modernização, desprezando a sua harmonia com os demais elementos, não pode se configurar como desenvolvido, pode, no máximo, ser um Estado modernizado.

Denota-se que o Texto Constitucional projeto este Estado desenvolvido e forte, o quão indispensável seja para que os fundamentos afirmados no seu artigo $1^{\circ}$ e os objetivos definidos no seu artigo $3^{\circ}$ venham a ser plenamente realizados. O que reflete, por fim, na garantia formal de que a ordem econômica assegurará a todos existência digna. Tais pressupostos são concatenados em decorrência de que a ordem econômica na Constituição de 1988 consagra um regime de mercado organizado, entendido como tal aquele afetado pelos preceitos da ordem pública clássica, segundo Vidigal (1998). Também nesse caminho, Silva Neto (2001, p. 135) conceitua a ordem econômica como "o plexo normativo, de natureza constitucional, no qual são fixadas a opção por um modelo econômico e a forma como deve se operar a intervenção do Estado no domínio econômico".

Nesse aspecto, Reale (1989) acrescenta que, com a nova ordem constitucional de 1988, um dirigismo constitucional foi estabelecido, tendo o artigo 170 implantado uma nova ordem econômica pregando por uma livre economia, onde os princípios da livre concorrência, da lealdade e da igualdade de competição são imperativos, admitindo-se a intervenção do Estado apenas com o fito de coibirem-se os abusos e preservar a livre concorrência, quer estatal, quer particular. Optou o legislador constituinte de 1988 por uma posição intermediária entre o liberalismo oitocentista, infenso a toda e qualquer intervenção do Estado, e o dirigismo estatal.

Ainda em conformidade com Reale (1989), adotou-se, assim, uma posição correspondente ao neoliberal ou social-liberalismo, enfatizando os ditos princípios, 
figurando inadmissível em um Estado Democrático de Direito a intromissão dirigida e ilimitada do Estado, admitindo-se a sua interferência apenas e tão somente com o fim de evitar a eliminação da concorrência, reprimindo o abuso econômico que visasse à obtenção de lucros ilícitos. O Estado passou, portanto, a ter uma função fiscalizadora, eis que a Constituição Federal de 1988 a admite apenas quando se dispõe a impedir o aumento arbitrário dos lucros e fixar e apurar as responsabilidades de empresas e empresários nos atos atentatórios contra a ordem econômico-financeira e a economia popular.

Ao exercer as funções determinadas nos artigos 173 e 174, o Estado é considerado agente. A Constituição consagra-lhe um papel ativo e não ativo. Trata-se de um papel próprio que lhe permite atuar na cena econômica, como explica Ferraz Júnior (1989, p. 76-86) quando expõe que, no Estado, não repousa a estrutura da ordem econômica, este não lhe impõe nem conforma as regras estruturais, não é fundamento da economia. A Constituição, nesse sentido, repudia a economia estatizada, o capitalismo do Estado, o dirigismo econômico, pois, ao contrário, acentua essencialmente o pluralismo da livre iniciativa e o sentido social, não discriminatório do trabalho humano como fundamento desta. Como agente normativo e regulador, o Estado, portanto, não se substitui ao mercado na configuração estrutural da economia.

É que, de um lado, não se pode visualizar a ordem econômica constitucional como produto de imposições circunstanciais ou meros caprichos constituintes, porém como resultado do confronto de posturas e texturas ideológicas e de interesses que, de uma ou de outra forma, foram compostos, para como peculiar estrutura ideológica aninhar-se no Texto Constitucional, em consonância com o que preleciona Grau (2010, p. 194).

Ademais, não se pode ser ingênuo a ponto de pensar que são as bases constitucionais da ordem econômica que definem a estrutura de determinado sistema econômico. A Constituição formal não constitui a realidade material. Por outro lado, não é possível aceitar um determinismo econômico sobre a realidade jurídica formal. Com efeito, é inegável que a Constituição tem força normativa, isto é, a Constituição pode ser um meio de transformar a realidade, como reflete Silva (2003, p. 722). Apesar de a Constituição ser capitalista, ela não deve ser interpretada estaticamente, mas ao reverso. Em decorrência deste dinamismo, o Texto Constitucional abre caminhos para que sejam instrumentalizadas modificações econômicas na conjuntura societal. 


\section{A VIGÊNCIADAINTERPRETAÇÃO PRINCIPIOLÓGICAEM DOMÍNIO ECONÔMICO}

É certo que os princípios, explicitados ou não, sempre fizeram parte da Constituição, mormente porque se configuram, concomitantemente, como instrumentos norteadores da concreção de determinados interesses, a fim de legitimar, nesse caso, a implementação de políticas públicas no âmbito tributário. Logo, a principiologia em domínio econômico é relevante mecanismo para que se possa melhor compreender a sistemática rede de interações econômicas na atualidade.

Focalizando nessas premissas, mostra-se oportuno, já de antemão, mencionar que os princípios são, na definição de Silva (2002, p. 877), as normas elementares ou os requisitos primordiais instituídos como base, como sustentáculo de alguma situação. Revelam o conjunto de regras ou preceitos que se fixam para servir de norma a toda espécie de ação jurídica, traçando, assim, a conduta a ser tida em qualquer operação jurídica. Deste modo, exprimem sentido mais relevante que o da própria norma ou regra jurídica. Mostram a própria razão fundamental de ser das coisas jurídicas, convertendo-se em perfeitos axiomas. Sem dúvida, significam os aspectos básicos, que servem de ponto de partida ou de elementos vitais do próprio Direito.

Nessa perspectiva, o artigo 170 da Constituição Federal de 1988 cataloga os princípios concernentes à ordem econômica, os quais operacionalizam a persecução dos objetivos a que se propõe o ordenamento jurídico e do cumprimento dos fundamentos do Estado brasileiro. A partir disso é que Fonseca (1998, p. 87-88) alude que para que estes fundamentos sejam concretizados e para que os fins sejam alcançados, necessário se faz adotar alguns princípios norteadores da atividade da ação estatal. É no Texto Constitucional que estão inseridos os valores mais basilares para a convivência social harmoniosa.

A existência, no ordenamento jurídico, de determinados princípios que, embora não enunciados em nenhum texto de direito positivo, desempenham papel de importância definitiva no processo de interpretação do direito, é inquestionável. A ordem econômica é, portanto, a aplicação de textos, não de normas, visto que o direito é alográfico, mas não apenas de textos, senão de textos e de fatos. E mais: interpretar/aplicar o direito é concretizá-lo, ir dos textos e dos fatos à norma jurídica geral e, em seguida, à norma de decisão, no desenvolvimento de uma prudência. Por isso não existe, no direito, uma única solução correta, senão várias, de acordo com Grau (2010, p. 160-161). 
Grau (2010, p. 161-162) aduz, ainda, que o que peculiariza a interpretação da Constituição, de modo mais marcado, é o fato de ser ela o estatuto jurídico do político, o que prontamente remete à ponderação de "valores políticos". Como, no entanto, esses "valores" penetram o nível do jurídico, na Constituição, quando contemplados em princípios - seja em princípios explícitos, seja em princípios implícitos ou em princípios gerais de direitos. Desde logo se antevê a necessidade de tomar tais princípios como conformadores da interpretação das regras constitucionais.

O que se passa, em verdade, é que a interpretação constitucional impõe ao intérprete a utilização de múltiplos métodos, se bem que primordialmente informados - e conformados - por uma linha de atuação que menos reflete uma opção preferencial por qualquer deles do que adesão à determinada postura ideológica. Assim como jamais se interpreta um texto normativo, mas sim o direito, não se interpretam textos normativos constitucionais, isoladamente, mas sim a Constituição, no seu todo. Não se interpreta a Constituição em tiras, em pedaços. A interpretação de qualquer norma da Constituição impõe ao intérprete, sempre, em qualquer circunstância, o caminhar pelo percurso que se projeta a partir dela - da norma - até a Constituição, conforme salienta Grau (2010, p. 163-164).

Nesse sentido, Gadamer (1999, p. 461) reflexiona que a compreensão adequada dos textos normativos, portanto, implica a sua atual e revigorante compreensão, em cada situação concreta, de uma maneira nova e distinta, porquanto compreender é sempre aplicar. A natural insuficiência da lei tomada em si mesmo, pela congênita deficiência de uma aplicação simples (abstrata), ao ignorar a situação hermenêutica onde se encontra o intérprete, que a interpreção seja uma tarefa prática não a transmuda para uma operação arbitrária.

Daí decorre a importância das normas-objetivo, que surgem definitivamente a partir do momento em que os textos normativos passam a ser dinamizados como instrumentos de governo. O direito passa a ser operacionalizado tendo em vista a implementação de políticas públicas, políticas referidas a fins múltiplos e específicos. A definição dos fins dessas políticas é enunciada, pois, precisamente em textos normativos que consubstanciam normas-objetivo e que, mercê disso, passam a determinar os processos de interpretação do direito, reduzindo a amplitude da moldura do texto e dos fatos, de modo que nela não cabem soluções que não sejam adequadas, absolutamente, a tais normas-objetivo, como explica Grau (2010, p. 164-165). 
A intervenção estatal na ordem econômica justifica-se, então, consoante Gomes (1986, p. 16) pela necessidade de submeter a vida econômica aos imperativos da justiça. A ordem econômica caracterizada por essa atitude ingerente do Estado não é manifestação típica da ordem política traçada na Constituição. Os princípios e preceitos orientados nesse rumo visam a introduzir no fortuito domínio da economia os ditames da justiça. Inconstitucionaliza-se a economia de mercado na sua variedade mista porque preserva e reabastece valores considerados necessários a uma organização justa da sociedade, independentemente de seu traçado político.

Perfilhando este entendimento, Pimenta (2002, p. 137) assevera que são as normas jurídicas inseridas na Constituição que representam uma tentativa do constituinte em conciliar os interesses opostos dos grupos sociais, tendo conteúdo econômico-social, função eficacial de programa, que, entretanto, obrigam os órgãos integrantes da organização política do Estado (Executivo, Legislativo e Judiciário), mediante a determinação dos princípios que por eles devem ser cumpridos.

A aplicação do direito - e este ato supõe interpretação - não é mera dedução dele, mas, sim, processo de contínua adaptação de suas normas à realidade e seus conflitos. Da mesma forma, a ordem jurídica, no seu evolver em coerência com as necessidades reais, embora haja de respeitar a Constituição, não se resume a uma mera dedução dela. A Constituição é um dinamismo. Assim, o significado válido dos princípios é variável no tempo e no espaço, histórica e culturalmente, sob a perspectiva de Grau (2010, p. 166).

Em um Estado de Direito tudo deve o quanto possível ocorrer com justiça. A questão da justiça se coloca efetivamente, sobretudo, quando uma coletividade de pessoas está destinada a compartilhar cargas e pretensões, que estão conexas com a vida em comum numa comunidade. De um modo geral: justiça pressupõe princípios, valores ou regras - estas entendidas como tendo um conteúdo equivalente aos anteriores. Se a meta é alcançar a justiça, não pode ser um princípio qualquer o princípio fundamental. O princípio deve ser antes de tudo adequado à realidade. A justiça é garantida primordialmente pela igualdade perante a lei, no Direito Tributário pela igualdade na distribuição da carga tributária. Do princípio fundamental devem ser deduzidos subprincípios e, em última instância, preceitos concretos. Assim surge um sistema jurídico, como destaca Tipke (2002, p. 13-18).

Dessa forma, Grau (2010, p. 168-170) sublinha que o intérprete da Constituição não se limita a compreender textos que participam do mundo do 
dever-ser, há de interpretar também a realidade, os movimentos dos fatores reais do poder, compreender o momento histórico no qual as normas constitucionais são produzidas, vale dizer, o momento da passagem da dimensão textual para a dimensão normativa. Cuida-se, então, de ideologia que se expressa nos princípios adotados na ordem jurídica, significando que esta é a que se comprometerá com o aspecto político, quando tomada enquanto direito positivo.

Os princípios, na sua interação, registram as marcas da ideologia constitucionalmente adotada. À luz por eles projetada, na sua globalidade, parte daquelas questões prontamente dilucidadas: a ordem econômica na Constituição de 1988 define opção por um sistema econômico, o sistema capitalista. Há nela, nitidamente, rejeição da econômica liberal do princípio da autorregulação da economia. Basta, para tanto, ler o artigo 170: a ordem econômica liberal é substituída por uma ordem econômica intervencionista, segundo a referência feita por Grau (2010, p. 311).

Isto ocorreu, de acordo com Vidigal (1977, p. 14), face às imperfeições do liberalismo, cujas principais podem ser resumidas no surgimento dos monopólios, no advento de cíclicas crises econômicas e no exacerbamento do conflito capital versus trabalho, aliadas à incapacidade de autorregulação dos mercados e concreção dos ideais de liberdade, igualdade e fraternidade. Surgiu, assim, a ordem econômica intervencionista. Nesse aspecto, Grau (2010, p. 312) reflete que a ordem econômica produzida pela Constituição de 1988 consubstancia um meio para a construção do Estado Democrático de Direito. A inexistência de contradição entre os princípios da participação e da soberania popular, a textura das regras constitucionais consideradas e, ainda, a atribuição, à sociedade, de legitimidade para reivindicar a realização de políticas públicas podem fazer do Estado efetivo agente da promoção do bem-estar.

Adentra neste contexto, então, o princípio republicano, que conduz ao princípio da generalidade da tributação, pelo qual a carga tributária, longe de ser imposta sem qualquer critério, alcança a todos com isonomia e justiça. Por outro raio semântico, o sacrifício econômico que o contribuinte deve suportar precisa ser igual para todos os que se acham na mesma situação jurídica. A lei tributária deve ser igual para todos e a todos deve ser aplicada com igualdade, de acordo com Carrazza (2000, p. 59). O princípio republicano, o autor ainda cita que, embora não tipifique mais uma "cláusula pétrea", continua a ser um dos mais importantes do direito positivo brasileiro.

Constata-se, dessa forma, que os princípios constitucionais sugerem uma direção para ordem econômica, sem perder de vista, porém, as normatividades 
jurídicas. Em que pese o Brasil tenha adotado a economia de mercado, o Estado não deixa de cumprir seu papel dirigente, à medida que intervém no controle da atividade econômica. Depreende-se, assim, que a partir da análise da interpretação principiológica, é que se pode visualizar o Estado enquanto agente normatizador e regulador das atividades econômicas, cumprindo seu papel de fiscalizar, incentivas e planejar o direcionamento do sistema econômico brasileiro. Por conseguinte, a interpretação da Constituição é dominada pelas forças dos princípios constitucionais também no domínio econômico.

\section{A DEMOCRACIA EM CURSO NA EFETIVAÇÃO DE POLÍTICAS PÚBLICAS TRIBUTÁRIAS}

Visualizou-se que a ordem econômica é indispensável na estrutura social, visto que é mediante a solidificação de suas bases que se pode implementar políticas públicas tributárias que afetem, sobejamente, a convivência entre os sujeitos. Nesse ponto é que se pode constatar a inter-relação desde domínio econômico com o processo democrático em curso. A economia não pode ser dissociada dos demais contextos, porque ela é parte integrante do sistema, seja jurídico, cultural, social ou político.

Nesse viés, com a falência do Estado protetor e o agravamento da crise social, o neoliberalismo, responsabilizando a política de intervencionismo pela estagnação econômica e pelo parasitismo social, propõe um ajuste estrutural, visando, principalmente, o equilíbrio financeiro, com uma drástica redução dos gastos sociais, uma política social seletiva e emergencial. A globalização torna o processo de formulação de políticas públicas mais complexo, por estarem em jogo, agora, em cada país, interesses internacionais representados por forças sociais com um forte poder de interferência nas decisões quando estas não são diretamente ditadas por organismos multilaterais, em consonância com a explicação feita por Teixeira (2002, p. 04).

A partir deste enfoque é que, no desempenho do seu novo papel, o Estado, ao atuar como agente de implementação de políticas públicas, enriquece suas funções de integração, de modernização e de legitimação capitalista. Tudo isso autoriza a conclusão de que afirmar a soberania econômica nacional como instrumento para a realização do fim de assegurar a todos existência digna e como objetivo particular a ser alcançado é definir políticas públicas voltadas à viabilização da participação da sociedade, em condições de igualdade, no mercado internacional, como enfatiza Grau (2010, p. 28-33). 
Neste campo econômico, a política de fortalecimento financeiro estatal, que vem sendo realizada mediante a utilização, ainda insuficiente, do mecanismo compensatório da repartição da receita federal, não esgota os instrumentos empregados para superar e corrigir os desníveis econômicos e as disparidades regionais. A União Federal, centro do poder nacional, assumiu a missão de promover o desenvolvimento regional nas áreas críticas, de modo a integrá-las no quadro mais amplo do desenvolvimento nacional. A eliminação das disparidades regionais ingressou na competência federal da União para atingir os objetivos da política nacional de desenvolvimento econômico. Nessa ótica, Rodrigues (2003, p. 66) destaca que, "apesar da boa consideração emprestada aos municípios na $\mathrm{CF} / 88$, infelizmente não lhes foi dada representação similar para participar das questões da União”. Isto se deve ao fato de que, segundo Ataliba (2001, p. 83), os Estados de Direito, que plasmam suas instituições com base no ideal republicano, com a consagração da tripartição - e consequente autonomia e independência - dos poderes, bem como lastreadas no império da lei e no princípio da isonomia, têm necessariamente um direito administrativo aberto, oxigenado, participatório, permeado de técnicas, institutos e peculiaridades, inúmeras vezes, contrastantes com a rapidez, eficiência, agilidade e desassombro que caracterizam os regimes que, em nome dessas características, atropelam direitos, ignoram a participação dos administrados e atuam surpreendentemente, comprometendo a segurança e a previsibilidade dos direitos.

Ocorre que, de acordo com as teorizações de Castilho (2002, p. 88), como forma de governo, a República caracteriza-se por conferir os poderes supremos a uma coletividade de pessoas. A República (coisa pública) é de todos, em igualdade de condições. O governante e o parlamento devem representar a vontade do povo, verdadeiros titulares do poder político. No regime republicano e dentro de um autêntico Estado Democrático de Direito, os mandatos são transitórios e os governantes respondem por suas decisões, ao contrário dos Estados autoritários e totalitários, em que o governante se perpetua no poder e age de acordo com seu arbítrio.

O que torna possível a República, ainda segundo Castilho (2002, p. 88), é o sistema representativo e o regime democrático, cujas características principais são o voto direto, secreto, universal e periódico e os direitos e as garantias individuais. Em nossa Constituição, esses valores são tidos como cláusulas pétreas e não podem sequer ser objeto de deliberação de proposta 
de emenda constitucional tendentes a aboli-los, conforme consta do artigo $60, \S 4^{\circ}$, da Constituição da República de 1988. É dentro desse espírito republicano que deve ser vista a tributação em nosso país. A exigência tributária só tem sentido em uma República se for para o bem de todos, como forma de garantir a prestação dos serviços públicos que o Estado está obrigado a fornecer. Num Estado Democrático de Direito, portanto, não há espaço para se utilizar tributo como pena, como se fazia em épocas mais primitivas.

A República é, então, a mescla entre dois regimes. O homem prudente é capaz de deliberar com vista ao bem viver em geral, é através do discurso político, da troca de opiniões com os outros indivíduos, que alcançará a decisão correta. Somente a forma de governo fundada em concordância com a natureza humana, ou seja, que possibilite ao homem realizar-se como animal social e racional, pode oferecer as condições para a vida digna. A República é o governo racional que se pode e se deseja realizar. Segundo o critério qualitativo, a oligarquia é o governo dos ricos, a democracia, o dos pobres, e a república, o da classe média. A república é o governo misto inspirado no ideal da Ética aristotélica, a "mediação", que se funda em um valor elevado e positivo de tudo o que está entre dois extremos, consoante afirma Bobbio (1997, p. 62).

De acordo com a visão de mundo teleológica de Aristóteles, a democracia deliberativa (a república) é a forma de governo que mais se assemelha à natureza humana, por isso é a mais natural. Assim, este regime é o que melhor se relaciona com a essência humana, pois é, também, a essência da pólis. O homem por natureza é um animal racional e político, e somente através de um governo dos muitos, vinculado com a razão prática (prudência) estabelecida por intermédio do diálogo democrático, é que se pode garantir um governo que satisfaça o ideal de vida humana que é o telos, ou seja, que é o bem dos homens, assim o homem é, por natureza, um animal democrático, na concepção de Barzotto (2003, p. 82).

Sob este enfoque, pode-se verificar que, conforme Kelsen (1993, p. 103), a democracia procedimental é entendida como um método capaz de criar a ordem social coletiva, ou seja, esta é a forma de governo que prevê regras e procedimentos que possibilitam aos cidadãos tomarem decisões. Tais regras não dizem respeito ao conteúdo dessas decisões, mas operam de forma a estabelecer quem são os cidadãos aptos a decidir e de que forma se realizam as decisões, já que a democracia é apenas uma forma, apenas um método de criação da ordem social. 
Daí se pode observar que a democracia não abandona por completo os ideais do liberalismo político, não estando desvinculado dele, já que parte do princípio da restrição do poder estatal frente a algumas esferas do interesse individual. Em outros termos, o sujeito deve ser protegido contra a ingerência do Estado e esta é a origem dos direitos e das liberdades fundamentais. Ainda segundo Kelsen (1993, p. 183), "a democracia, para não virar uma tirania da maioria, se vale dos ideais liberais. Porém, não mais com o propósito de proteger o indivíduo, mas para proteger a minoria contra a ação arbitrária da maioria".

Seguindo esta compreensão, Agra (2005, p. 13) elucida que o Republicanismo, considerado como forma de governo pautada por um núcleo axiológico, configura-se como teoria política que pode realmente assegurar a liberdade dos cidadãos, impedindo que interesses privados ou a vontade de um déspota possam privá-los de seus direitos. Por estar umbilicalmente atrelado ao princípio democrático, ao autogoverno da população, ao princípio da isonomia, é a forma de organização política que melhor pode enfrentar as dificuldades que assolam as sociedades pós-modernas.

Assim como o liberalismo, o sistema capitalista, de igual modo, sofreu mudanças ao longo de toda a sua história e, no atual Estado contemporâneo, sofreu mutações em sua forma, uma vez que este não está livre para gerir as relações econômicas, mas sim, regulado por normas emanadas do ente estatal no intuito de estabelecer limites a essas práticas comerciais. Normas estas compreendidas, inclusive, na própria Carta Constitucional, no Título referente à Ordem Econômica (artigo 170 e seguintes). Nesse aspecto, Pereira (1980, p. 200) menciona que o mundo moderno apresentado, hoje, é o que se denomina de democracia econômica, diversa da tese de abstenção do sistema liberal, que não punia excessos ou abusos, mas sim um sistema que procura formar nova mentalidade nas elites administrativas, instrumentando-as para que se sobreponham os ideais de um melhor rendimento em favor do homem.

É nestas ambiências que se justificam as políticas tributárias. A política econômica que compreende toda a atividade produtiva cedeu lugar à política financeira, que se ocupa do direito público e esta, por sua vez, deu origem à política tributária, a qual passou a cuidar, exclusivamente, das atividades estatais concernentes aos tributos. Para Becker (1963, p. 458), a política fiscal discrimina diferentes espécies econômicas de rende e de capital para sofrerem diferentes incidências econômicas de tributação, no intuito de 
alcançar seus objetivos econômico-sociais. A política fiscal deve ser entendida, ainda, como o conjunto de medidas relativas ao regime tributário, gastos públicos que se desdobram em diversos seguimentos. Ou seja, a política fiscal pode utilizar-se dos tributos e dos gastos do governo para regular a atividade econômica sem desconsiderar os ditames da política monetária.

Dessa forma é que vai sendo engendrado um direito da organização dos mercados. Na acepção de Vidigal (1977, p. 47), este direito pode ser examinado como uma disciplina jurídica corretora do conjunto das distorções características das soluções de liberdade de mercado, abrangendo não apenas as distorções que afetam a competição, como as que induzem repartição desigual e as que alimentam flutuações em direção à crise. Toda política econômica se desenvolve através de normas de direito econômico, ou de repercussão econômica, mas nem sempre estas se referem a uma política econômica. Esta pode ser compreendida como uma orientação programática, de natureza econômica, fixada por determinado governo, não as diretrizes básicas estabelecidas pela ordem econômica constitucional. Tais balizas não são passíveis de alteração por aquela, que se deve conformar aos propósitos e âmbito material de sua formulação normativa.

Com base nestas concepções que Comparato (1965, p. 11-17) afirma que todo o direito econômico no país se funda na Constituição, seja decorrente de preceitos inseridos na ordem econômica formal, seja naqueles veiculadores de matéria econômica, esparsos no texto, sobretudo os que se referem às competências dos entes federados. Com maior ou menor grau de eficácia, o direito econômico veio regrar a presença do poder público na seara econômica. A edição de normas jurídicas disciplinadoras da presença estatal nesse campo (seja para ordenar sua ação direta ou para estabelecer os parâmetros na atividade privada), tornou-se o grande elenco normativo que estabelece as relações entre o interesse público (interesse geral, representado pelo Estado), e a atividade econômica em sentido amplo.

Segundo Bonavides (2003, p. 225), a ideia de que um mínimo de Estado corresponderia a um máximo de liberdade restou ultrapassada ou superada. Sem Estado social e sem Constituição, não há como criar a ordem econômica e social de uma democracia pluralista, mormente na sociedade de massa do século XXI. Verifica-se, então, que a atuação estatal no domínio econômico pode se dar de diversas formas, sempre com fins de implementar a política econômica juridicamente adotada. 
Ao dispor acerca da atuação estatal, Bastos (2003, p. 258) afirma que nos momentos de grande demanda, e nos momentos de crise, atua incentivando, instigando o mercado. É por isso que se tem, no sistema brasileiro, bem como na maior parte do mundo, o Estado como agente normativo e regulador da ordem econômica. Sendo assim, uma legítima política tributária deve ser fundada em diversos fatores e não apenas embasada na arrecadação procedida pelo Estado. Tais políticas devem atender aos ditames constitucionais, visando o desenvolvimento socioeconômico e garantido os direitos dos sujeitos. Logo, infere-se que a democracia em curso demanda a efetiva implementação das políticas públicas tributárias.

\section{CONSIDERAÇÕES FINAIS}

A partir dos fundamentos confrontados foi possível verificar que a compreensão sobre a ordem econômica atualmente vigente reside nas amplas e complexas atuações do Estado neste domínio, a qual afeta não só o mercado, mas também, e de forma principal, os modos de convivência societal. Isto faz com que o intervencionismo estatal seja condicionado pela principiologia, especialmente a fim de prevenir e reprimir os abusos contra a ordem econômica em favor da igualdade e do bem-estar dos sujeitos.

Constatou-se, de igual modo, a imprescindibilidade de se construir a esfera econômica como um fundamental espaço de articulação de políticas públicas tributárias no enfrentamento das disparidades sociais e regionais. É na pretensão desta harmonia social que os princípios constitucionais funcionam como verdadeiros instrumentos do sistema normativo na (re)estruturação estatal neste âmbito, orientando, por conseguinte, todas as políticas socioeconômicas desenvolvidas.

A ingerência estatal na economia é, portanto, reflexo dos processos democráticos que permeiam a conjuntura contemporânea, resultado da conscientização dos indivíduos de se mostrar essencial reivindicar os direitos salvaguardados no Texto Constitucional. O Estado, assim, poderá atender aos objetivos sociais mediante uma melhor distribuição das riquezas produzidas no país, na efetiva satisfação de determinadas necessidades societais, das políticas de investimentos em áreas cruciais para o desenvolvimento econômico brasileiro, e assim sucessivamente. 
Nesse contexto da globalização econômica, tais objetivos podem ser almejados por intermédio da implementação de políticas públicas tributárias e não necessariamente pela imposição tributária. Infere-se, então, que estas políticas, além de constituírem meios adequados para fomentar as finalidades constitucionais, que sustentam a intervenção do Estado sobre o domínio econômico, são relevantes mecanismos na procura pela igualdade, pelo bemestar dos indivíduos e, como corolário, por um ambiente democraticamente mais justo.

Perspectivando nesse sentido, é relevante destacar, ainda e por fim, que a ordem econômica na Constituição Federal de 1988 se constitui em uma esfera aberta, ao considerar que o Texto Constitucional apresenta um dinamismo por conter cláusulas transformadoras, tanto no atinente ao ambiente econômico quanto nas demais ambiências da vida social. Logo, a construção de reformulações nos modelos paradigmáticos transita pela análise da coerência entre esta ordem econômica com as aspirações presentes. Isto porque a ordem econômica pode instrumentar a busca da efetivação, em sua plenitude, dos interesses sociais na democracia em curso.

\section{REFERÊNCIAS}

AGRA, Walber de Moura. Republicanismo. Porto Alegre: Livraria do Advogado, 2005.

ATALIBA, Geraldo. República e Constituição. 2. ed. São Paulo: Malheiros, 2001.

BARZOTTO, Luis Fernando. A Democracia na Constituição.

São Leopoldo: Unisinos, 2003.

BASTOS, Celso Ribeiro. Curso de Direito Econômico. São Paulo: Celso Bastos, 2003.

BECKER, Alfredo Augusto. Teoria Geral do Direito Tributário. São Paulo: Saraiva, 1963.

BOBBIO, Norberto. A Teoria das Formas de Governo. 10. ed. Brasília: UnB, 1997. 
BONAVIDES, Paulo. Teoria do Estado. 4. ed. São Paulo: Malheiros, 2003.

BRASIL. Constituição da República Federativa do Brasil, de 05 de outubro de 1988. 15. ed. São Paulo: Saraiva, 2013.

CANOTILHO, José Joaquim Gomes. Constituição Dirigente e Vinculação do Legislador. 2. ed. Coimbra: Coimbra, 2001.

CARraZZA, Roque Antonio. Curso de Direito Constitucional Tributário. 14. ed. São Paulo: Malheiros, 2000.

CASTILHO, Paulo Cesar Baria de. Confisco Tributário. São Paulo: Revista dos Tribunais, 2002.

COMPARATO, Fábio Konder. O Indispensável Direito Econômico. São Paulo: Revista dos Tribunais, 1965.

ELALI, André de Souza Dantas. Um Exame da Desigualdade da Tributação em face dos Princípios da Ordem Econômica. Revista Tributária e de Finanças Públicas. Recife, v. 81, 2008. p. 11-29.

FERRAZ JÚNIOR, Tércio Sampaio. A Economia e o Controle do Estado. Revista de Direito Público, São Paulo, n. 91, p. 76-86, 1989.

FERREIRA, Eduardo Paz. Valores e Interesses - Desenvolvimento Econômico e Política Comunitária de Cooperação. Coimbra: Almedina, 2004.

FONSECA, João Bosco Leopoldino da. Direito Econômico. 2. ed. Rio de Janeiro: Forense, 1998.

GADAMER, Hans-Georg. Verdade e Método. Petrópolis: Vozes, 1999.

GOMES, Orlando. Ensaios de direito civil e de direito do trabalho. Rio de Janeiro: Aide, 1986.

GRAU, Eros Roberto. A Ordem econômica na constituição de 1988. 14. ed. São Paulo: Malheiros, 2010. 
KELSEN, Hans. A Democracia. São Paulo: Martins Fontes, 1993.

MOREIRA, Vital. Economia e constituição: para o conceito de Constituição Econômica. 2. ed. Coimbra: Coimbra, 1979.

PEREIRA, Afonso Insuela. O Direito econômico na ordem jurídica. 2. ed. São Paulo: José Bushatsky, 1980.

PÉREZ LUÑO, Antônio Enrique. Derechos humanos, estado de derecho y constitución. 7. ed. Madrid: Tecnos, 2001.

PIMENTA, Paulo Roberto Lyrio. Contribuições de intervenção no domínio econômico. São Paulo: Dialética, 2002.

REALE, Miguel. Constituição e economia. O Estado de São Paulo, São Paulo, 21 Jan. 1989.

RODRIGUES, Hugo Thamir. Harmonização solidária das políticas tributárias municipais: um princípio constitucional geral, implícito, delimitador das ações tendentes ao cumprimento da função social dos municípios. 2003. Tese (Doutorado em Direito) - UFSC, Florianópolis, 2003.

SILVA NETO, Manoel Jorge e. Direito constitucional econômico. São Paulo: LTr, 2001.

SILVA, De Plácido e. Vocabulário jurídico. 19. ed. Rio de Janeiro: Forense, 2002.

SILVA, José Afonso da. Curso de direito constitucional positivo. 22. ed. São Paulo: Malheiros, 2003.

TEIXEIRA, Elenaldo Celso. O papel das políticas públicas no desenvolvimento local e na transformação da realidade. Salvador: AATR, 2002.

TIPKE, Klaus. Moral tributária do estado e dos contribuintes. Madrid: Marcial Pons, 2002. 
VIDIGAL, Geraldo de Camargo. A Constituição brasileira - 1988:

interpretações. Rio de Janeiro: Forense, 1988.

VIDIGAL, Geraldo de Camargo. Teoria Geral do Direito Econômico.

São Paulo: Revista dos Tribunais, 1977.

Artigo recebido em 02/09/13 e aprovado em $01 / 11 / 13$

Como citar: COSTA, Marli Marlene Moraes da; D’OLIVEIRA, Mariane Camargo. Interações econômicas na interface com a implementação de políticas públicas: a democracia em curso. Scientia Iuris, Londrina, v.17, n.2, p.55-74, dez.2013. DOI: 10.5433/2178-8189.2013v17n2p55. 